\title{
A ARQUEOLOGIA E A CULTURA AFRICANA NAS AMÉRICAS.
}

\author{
Pedro Paulo Abreu Funari*
}

\section{INTRODUÇÃO}

A escravidão e a cultura negra no Brasil têm constituído, ao longo dos anos, um campo de estudo constante e crescente. Desde o início do sećulo, o negro tem sido objeto de referência por parte dos pensadores que se ocuparam da constituição de uma identidade nacional brasileira. Nas últimas décadas, com a intensificação da produção acadêmica sobre a cultura africana, surgiram vertentes e especializações, intensificaram-se os debates e as contraposições interpretativas, atestando o aprofundamento dos estudos sobre o tema. No entanto, permanece válida a afirmação de Stuart B. Schwartz (1977:69) de que "em grande medida, a despeito de uma bibliografia extensiva e sempre crescente, a História da escravidão no Brasil resta por escrever". Cinco anos depois, também para Emília Viotti da Costa (1982:45) “a conclusão a que se chega é de que, apesar dos louváveis esforços que os historiadores têm feito nos últimos anos, a questão escrava no Brasil é, ainda, uma questão aberta". A produção científica tem sido grande, seja nas Ciências Sociais (cf. Reis 1988: 57), seja na História, a ponto de se calcular (Gutiérrez 1988: 185), que, na década entre 1976 e 1985, foram divulgados 276 trabalhos, ou um, artigo novo a cada quinzena. Assim, só sobre a escravidão, há 407 títulos arrolados por Gutiérrez \& Monteiro (1990) e, sobre a cultura afro no Brasil, 1965 títulos recolhidos por Alves (1976).

Uma característica marcante da produção recente refere-se à sua preocupação em escapar à unilateridade do "olhar branco" sobre a cultura africana. O discurso (Schwartz 1987: 16) e olhar dos brancos (Slenes 1988:203)

Estudos Ibero-Americanos. PUCRS, v.XVII, n.2, p.61-71, dezembro, 1991 
têm sido objeto de análises críticas e aumenta a preocupação em escapar-se das restrições inerentes ao registro dominante. "Importante vertente da historiografia contemporânea tem se caracterizado, dentre outros aspectos, pela recuperação e valorização de fontes desprezadas pelos historiadores tradicionais. Estes têm permitido a reconstrução de aspectos da realidade mais próximos da vida quotidiana, e a desmistificação da visão de mundo erigida a partir da documentação oficial, bem como um outro "olhar" sobre aqueles que aí aparecem de forma oblíqua ou mesmo figurativa" (Guimarẽs et alii 1990: 01). Escravidão, cultura afro-brasileira e "problema negro" (Cardoso 1982: 108) constituem questões não apenas acadêmicas mas, principalmente, sociais. À diferença do que se passa nos Estados Unidos, não possuímos, aqui, um "público negro atento, qualificado para absorver e criticar a produção científica" (Oliveira e Oliveira 198: 69). Os anseios das comunidades e entidades afro, não apenas em nosso país, mas em outras partes do continente americano, de "resgatar, realçar e desenvolver a identidade étnica, cultural e histórica afro" (Movimiento Nacional Cimarrón de Colombia, in Friedemann 1988:4) passa, contudo, por uma superação das limitações impostas pelo referencial branco da documentação escrita dominante. Neste sentido, a Arqueologia, como estudo do quotidiano através da cultura material, permite chegar ao escravo, captando sua voz, nunca escrita, mas materializada nos objetos e espaços por eles produzidos e usados.

A Arqueologia Brasileira, para estar à altura dessa tarefa, precisa, no entanto, tomar consciência de sua missão e comprometimento com a sociedade nacional. Passa-se, com a Arqueologia Brasileira, algo semelhante ao que aflige a Arqueologia Africana e podemos aplicar, ao nosso caso, as considerações de Michael Rowlands (1989: 281-2): "certas prioridades da Arqueologia Africana precisam ser repensadas. Uma destas é a necessidade de uma Arqueologia Histórica da Åfrica que se preocupasse mais diretamente com a compreensão das origens das condições políticas e econômicas contemporâneas que afligem o continente... a Arqueologia Africana parece por demais preocupada em demonstrar seu valor para uma audiência internacional precocupada com "grandes questões" da Pré-História do homem". De fato, a Arqueologia Histórica pode contribuir, de maneira significativa, para a abordagem de uma série de questões levantadas, explícita ou implicitamente, pelas pesquisas sobre a escravidão e a cultura afro.

Em primeiro lugar, e respondendo aos recentes chamamentos aos estudos locais (Martins \& Martins 1984: 146) e monográficos (Machado 1988: 143), a cultura material permitiria esclarecer a situação concreta e o modo 
de vida de escravos, senhores, quilombolas e pobres ("desclassificados"). No momento atual, a maior parte da informação que tem sido analisada refere-se à cultura material tal como refletida nos documentos escritos ou figurativos. Assim, em suas monografias sobre Vassouras e Rio Claro, Warren Dean (1976) e Stanley Stein (1969) referem-se ao quotidiano das fazendas em termos absolutamente generalizantes, sem que possamos avaliar em que medida estas generalizações seriam constatadas, arqueologicamente, nas fazendas da região. "Banheiros não existem na maioria das fazendas" (Stein 1969: 53): qual seria esta maioria? Ou, em que medida os banheiros não estão descritos nos documentos? Ainda mais, na ausência de banheiro, que tipo de fossa sanitária era utilizada? "A casa-grande era geralmente simples e sem ornamento" (Dean 1976:45). "Às vezes, havia um balcão atrás de um dos lados, dando para o terreiro, grande quadrilátero pavimentado, total ou parcialmente cercado pela senzala" (Valverde 1965:12). Generalizações como estas deveriam ser o resultado de inúmeras pesquisas em fazendas reais para adquirirem o valor documental que precisariam possuir para se tornarem referenciais seguros.

Para que possamos avaliar o potencial da Arqueologia Histórica aplicada ao conhecimento da cultura afro, talvez a melhor maneira seja atentar para os avanços conseguidos, nesta área, pela Arqueologia Norte-Americana. Na medida em que o trabalho consiste no "determinante principal da sociedade escravista" (Schwartz 1988:10), a Arqueologia das fazendas escravistas tem consistido numa das principais áreas de pesquisa e tem produzido resultados particularmente instigantes. Pode avaliar-se a produção científica norte-americana, nesta área, pelos mais de quatrocentos títulos citados no número especial de Historical Archaeology sobre o tema, publicado em 1990.

\section{DAS FAZENDAS DESCRITAS ÀS FAZENDAS CONCRETAS}

Na introdução ao volume "A Arqueologia Histórica das Fazendas Sulistas", Charles E. Orser Jr. (1990:6) ressaltava que "as questões às quais os arqueológos brasileiros historiadores que estudam o Sul votam, cada vez mais, sua atenção, referem-se ao racismo, à percepção, ao simbolismo, às relações sociais e à persistência cultural". Na verdade, o que caracteriza a Arqueologia Histórica é seu foco em problemas associados ao capitalismo, em particular, aqueles cujo acesso privilegiado ou único se dá através da cultura material. Assim, "a Arque ologia Histórica examina o capitalismo e seus vários compo- 
nentes - colonialismo, imperialismo, industrialização, luta de classes e formações sociais - como temas históricos que não são propriamente nem 'históricos' nem 'antropológicos' apenas, mas ambos a uma só vez" (Orser 1988: 315). Não é, pois, à toa que a alienação e a luta de classes (cf. Handsman 1985:6) fundam a própria Arqueologia Histórica enquanto estudo do quotidiano, do popular e do trivial. Se o povo custa a aparecer no documento escrito, se quando ali aparece não é senão como referências de outrem, se para chegarmos a ele a fonte se nos interpõe antes como obstáculo a ser superado do que como acesso, esta mesma massa anônima domina o registro material: nele, sobeja o povo! "Podemos brincar, folgar, e cantar em todos os tempos que quizermos sem que nos empeça e nem seja preciso licença" (Stein 1977: 81). Estes e outros anseios dos escravos, rarissimamente reportados pelas fontes escritas, materializam-se nos instrumentos musicais, nos brinquedos, nas garrafas e em tantas coisas mais, feitas ou utilizadas pelos próprios escravos, cujos restos constituem o principal objeto da Arqueologia Histórica.

As pesquisas arqueológicas das fazendas norte-americanas têm se direcionado, justamente, "não para determinar as proporções do mesmo tipo de itens em todos os sítios (ou seja, de conzinhas, roupas, etc); o importante é entender como estes artefatos eram usados, nesta formação de classe, na luta de classes, na alienação e na mudança social"' (Orser 1989:37). Isto significou uma mudança de atenção da casa-grande para a senzala (Orser 1988:314), sem deixar de lado, no entanto, a interrelação, envolvendo espaço e poder, entre ambas as partes, da fazenda (Orser 1988:320-1). "Uma das mais engenhosas formas de resistência dos escravos envolvia a instituição de uma hierarquia de trabalho que atuava em direta oposição àquela imposta pelo senhor. Nesta hierarquia construida pelos escravos, os escravos nas mais altas posições eram os menos favorecidos pelo senhor" (Orser 199:116). As evidências dessas hierarquias jamais foram relatadas por escrito, são reconstruiveis apenas através dos vestígios materiais em que se baseavam. Estas hierarquizações materiais não são aplicáveis apenas ao estudo da escravidão mas, também, à comunidade negra em si e às suas transformações culturais enquanto parte das camadas populares da moderna sociedade capitalista. Como relevam K. L. Brown e D. C. Cooper (1990: 19), "africanos e afro-americanos podem ser, com freqüência, "invisíveis" na História escrita mas, através da pesquisa arqueológica levada a cabo cuidadosamente, não precisam continuar a sê-lo". De fato, "os africanos tornaram-se afro-americanos; neste processo de aculturação, adaptaram a cultura material euro-americana em alguns de seus sistemas comportamentais africanos. As escavações fornecem evidências claras de 
que hierarquias econômicas e políticas existiam no interior da comunidade afro tanto durante o período de escravidão como após a abolição. De fato, os dados sugerem que uma grande continuidade existiu, no interior da comunidade, nos dois períodos" (Brown \& Cooper 1990: 8; 11).

A "História dos não-organizados" (= history of the inarticulate, Singleton 1990: 72), da gente simples, reflete-se, na Arqueologia das fazendas, em quatro tendências, segundo Howson (1980: 78): "1 - os arqueólogos começam a encarar a cultura dos escravos como elemento chave para a compreensão da estrutura social e sua transformação nas fazendas sulistas; 2 - o sentido da herança africana está sendo examinado criticamente; 3 - os estudos da cultura material começam a ajudar na formulação de questões sobre categorias culturais significativas e sobre a mudança social; e 4 - uma abordagem privilegiando a ação social está suplantando o modelo de status, no que se refere às relações sociais nas fazendas".

Na medida em que "a cultura material não pode ser entendida cómo refletindo, simplesmente, relações sociais, mas como algo que participa, ativamente, de sua criação, funcionamento e manutenção" (Howson 1990:88), a correlação entre o comportamento humano e os objetos (Holland 1990:61) e as possíveis inferências a nível da estratificação social (Stine 1990:49) estão no centro da pesquisa arqueológica. Não se trata, portanto, de estudar os escravos isoladamente, mas em interação com feitores e senhores, em termos de alianças, indiferenças e antagonismos (Babson 1990:21). Neste contexto, a cultura material do fazendeiro consiste em parte integrante essencial do sistema escravista e seu estudo, em conjunção com as evidências dos outros segmentos sociais, torna-se indispensável. Assim, "a ideologia da Arquitetura (i.e. da elite) mascara não porque seja algo errado mas porque articula, simultaneamente, um sistema específico de dominação e o apresenta como algo inevitável, eterno, como senso-comum inegável. Os fazendeiros adotaram, desse modo, motivos da arquitetura romana clássica não como uma me táfora específica, mas como parte de uma tentativa geral de apropriar-se de uma aura e autoridades ahistóricas próprias à cultura clássica, fazendo com que relações específicas de dominação parecessem atemporais e inevitáveis" (Epperson 1990:31). No entanto, talvez a mais importante contribuição destes estudos recentes resida no questionamento constante dos modelos interpretativos, como ressalva Orser (1990:6) ao referir-se aos artigos publicados em Historical Archaeology (24,4, 1990): "os autores deste volume, ao desafiar muitas idéias acadêmicas correntes, tentam fazer a Arqueologia Histórica avançar. 
Se todas as idéias expressas aqui forem, no futuro, refutadas por outros pesquisadores, o objetivo mais amplo deste volume terá sido alcançado".

\section{O POTENCIAL DA ARQUEOLOGIA HISTÓRICA PARA O CONHECIMENTO DA CULTURA AFRO NO BRASIL}

Na partilha do espólio do Dr. José Ribeiro Leite Zamith, encontra-se a descrição do capital da Fazenda Saudade, localizada no Vale do Paraíba, avaliado em 1877. No documento inédito citam-se os escravos (66, no valor de 47:000\#000), os animais ( 3 , no valor de $143 \# 000$ ) e as seguintes construções e objetos:

Casas e obras: casa de morada (8:000\#), paiol (800\#), enfermaria (500\#), senzallas velhas (960\#), 2 telha 〈d〉os (320\#), seva (150\#), engenho e machinas (9:400\#), terr(eir)os (1:000\#), tanqués (600\#), moendas velhas (20\#).. 21: $750 \# 000$.

Móveis: 2 carroças, 1 carro, 1 carretão, mobilia, trem de cozinha, 5 tuyas de cobre 2: $272 \# 800$.

Esta sumária evidência escrita pouco nos revela sobre a disposição espacial dos edifícios da fazenda, sobre seus cômodos internos, com seus diferentes tamanhos e disposições. Também os artefatos móveis não merecem atenção especial. Mais ainda: note-se que toda a cultura material associada aos subalternos e escravos resume-se a duas palavras do discurso escrito (senzallas velhas). A partir de documentos oficiais deste tipo, tem-se assentado, forçosamente, a historiografia contemporânea sobre a escravidão no Brasil. Na medida em que possuimos vestígios materiais de centenas de fazendas escravistas, datadas desde a época colonial até ocupações mais recentes, o estudo arqueológico dessas unidades produtivas revelaria, pondo à prova as diferentes interpretações teóricas, as estruturas materiais concretas de funcionamento e transformação desse sistema econômico.

Se nossa atenção volta-se para a cultura afro, contudo, o locus mais adequado para seu estudo não reside na unidade produtiva. A fazenda escravista, enquanto unidade produtiva (Orser 1990:115) por excelência, funcionava como instituição disciplinar que tendia a inibir, coibir e delimitar as expressões culturais não aprovadas pelos senhores. $O$ grau de autonomia cultural do elemento afro pode ser mais claramente delimitado quando abandonamos a fazenda, espaço disciplinar (cf. Foucault 1977: 190) nesta instituição ainda tradicional mas já capitalista e, portanto, "vigilante" (cf. Giddens 1987:158), 
e buscamos a organização autárquica dos negros em quilombos. Assim como a greve consiste numa resistência sistêmica do proletariado ao capitalismo, a fuga dos escravos não se resume a fenômeno acidental mas adquiria uma constância (Moura 1987:31), constituindo parte essencial do próprio escravismo. "O quilombo foi, inconstestavelmente, a unidade básica de resistência do escravo. Pequeno ou grande, estável ou de vida precária, em qualquer região em que existia a escravidão, lá se encontrava ele como elemento de desgaste do regime servil" (Moura 1972:87). As fugas de escravos e a constituição de assentamentos de fugitivos eram ubíquas a tal ponto que apenas podemos avaliar sua extensão pela presença, em nosso campo, de centenas de topônimos referentes a quilombos.

Ferdinand Denis (1980:155-6), consciente da constância das fugas, constatava, em 1838, que os negros fugitivos "persistem neste gênero de vida deplorável e formam os quilombos no centro das florestas do litoral". Os próprios fazendeiros, ante à multiplicação dos quilombos, chegavam a responsabilizar o executivo por sua indiferença face ao problema (Beiguelman 1982. 23). O Estado, por sua parte, pouco fazia para preservar o estatuto jurídico dos africanos livres (Tavares Bastos 1975: 68), dificultando a reinserção do negro na sociedade branca e reforçando a atração exercida pelos quilombos perante à comunidade afro. Décio Freitas (180:43) propôs a caracterização de, ao menos sete tipos de quilombos no Brasil: 1 - agrícolas; 2 - extrativistas; 3 - mercantis; 4 - mineradores; 5 - pastoris, 6 - de serviços, 7 - predatórios.

Do ponto de vista cultural, contudo, o quilombo revela-se como evidência potencial da autonomia afro na América. Fora do controle branco, podia o africano forjar sua própria identidade. Identidade marcada pelas contradições de sua condição de cultura de fugitivos do escravismo (cf. Funari 1991). Não se trata, portanto, da idealização da cultura quilombola como desprovida de hierarquias e relações interiores conflitiva. De qualquer forma, entretanto, ainda que as distinções culturais que fazemos sejam arbitrárias e analíticas (cf. Rosenberg 1980:152), o conceito de identidade cultural quilombola autônoma permite melhor recortar a realidade expressiva do africano rebelde ao escravismo.

Neste sentido, o quilombo como categoria documental arqueológica, representa a única via de acesso direto à cultura específica e autarquicamente afro. A abundância de quilombos no Brasil constitui, assim, um manancial precioso de informações a ser pesquisado. Pelos poucos estudos arqueológicos já levados a cabo, pode entrever-se o potencial destes sítios. Como afirmava 
Paulo Zanettini (1991: 16), coordenador do Projeto Etnoarqueologia do Negro no Mato Grosso, cabe investigar quais os "indicadores de fenômenos culturais ligados à atividade pouco pesquisados do ponto de vista arqueológico". Carlos Magno Guimarães e Ana Lúcia Duarte Lanna (1980.162), pioneiros neste estudo, chamavam a atenção para o fato que o "quilombo", além de um foco de resistência à escravidão, foi também um foco de preservação da cultura negra pois ai o negro podia expressar livremente os elementos de sua cultura". Podemos avaliar o grau de autonomia expressiva destes fugitivos por uma pintura reproduzida em Guimarães \& Lanna (1980:163 = FIGURA 1). Escapando aos padrões estéticos da arte pictórica erudita, o autor anônimo deste desenho utilizou-se de forte estilização: com poucos traços expressa, de forma abstracionista, a figura humana. Sua elaboração estética, fruível apenas pela erudição do Século XX, demonstra que o quilombola não havia sido simplesmente aculturado, procurando imitar, grotescamente, os padrões eruditos. Possuia expressividade própria, criativa antes que imitativa. Todo o universo material do quilombo, das habitações e sua forma, aos objetos de uso quotidiano, tais como garrafas, vasilhas e cachimbos, arqueologicamente recuperáveis, permitem resgatar a especificidade da cultura afro.

$\mathrm{O}$ assentamento quilombola com maiores referências na tradição textual (Carneiro 1988) e cujos restos materiais abrangem uma imensa área, Palmares, consiste no objeto de estudo arqueológico mais promitente. Palmares, estudado já monofraficamente a partir da documentação escrita (Santos 1985; cf. Freitas 1984, com bibliografia anterior), fornece a oportunidade única de analisar, através da cultura material, a organização espacial e a vida quotidiana da sociedade autônoma e sua transformação ao longo de diversos decênios. É neste contexto que o Instituto Brasileiro de Estudos Africanistas ou IBEA, sob a direção de Clóvis Moura, a Universidade Estadual de IIlinois, na pessoa do Diretor do Centro de Pesquisas Arqueológicas do Meio-Oeste, Charles E. Orser Jr. e o autor destas linhas, preparam um projeto de pesquisa arqueológica na área. Sob sua direção, o Projeto Arqueológico de Palmares envolverá, num cronograma de execução plurianual, não apenas arqueólogos como, também, historiadores, antropólogos e outros cientistas sociais nas tarefas de prospecção e escavação arqueológicas e no estudo e interpretação do material. O projeto reveste-se de importância tanto para o conhecimento da cultura afro no Brasil como, em termos gerais, para o aprofundamento de nossa compreensão da autonomia cultural africana em solo americano.

Esperamos que, ao trabalharmos com o mais significativo monumento de resistência ao escravismo, possamos estabelecer as bases para o estudo pos- 
terior dos inúmeros quilombos espalhados por todo o continente americano. $\mathrm{O}$ envolvimento das comunidades negras e das associações afro-brasileiras neste processo de resgate da cultura afro, reforça o caráter social do projeto científico e visa restabelecer os vínculos tão necessários entre a ciência e a sociedade que, afinal, a justifica. A Arqueologia Histórica poderá, desta forma, contribuir para que a consciência da cultura afro, já presente nos movimentos sociais, encontre em Palmares as raízes de sua autêntica originalidade.

* Departamento de História UNESP

ASSIS - SP

\section{OBRAS CITADAS}

ALVES, H. L. (1976). Bibliografia Afro-Brasileira. São Paulo, Ed. H.

BABSON, D. W. (1990). The archaeology of racism and ethnicity on Southern Plantations, Historical Archaeology, 24, 4, $20-8$.

BEIGUELMAN, P. (1982). Introdução a Joaquim Nabuco: teoria e práxis, in BEIGUELMAN, P. (org.), Joaquim Nabuco. São Paulo, Ảtica, 7-50.

BROWN, K. L. \& COOPER, D. C. (1990). Structural continuity in an African-American Slave and Tenant community, Historical Archaeology, 24, 4, 7-19.

CARDOSO, C. F. S. (1982). Agricultura, escravidāo e capitalismo. Petrópolis, Vozes (1979).

CARNEIRO, E. (1988). O Quilombo de Palmares. São Paulo, Cia. Ed. Nacional.

DEAN, W. (1976). Rio Claro, a Brazilian Plantation System, 1820-1920. Standford, Standfor University Press.

DENIS, F. (1980). Brasil. Belo Horizonte, Itatiaia/Edusp (1888).

EPPERSON, T. W. (1990). Race and the disciplines of the Plantation, Historical Archaeology, 24, 4, 29-36.

FOUCAULT, M. (1977). Discipline and Punish. Londres, Allen Lane.

FREITAS, D. (1980). O escravismo brasileiro. Porto Alegre, E. S. T. S. C.

FREITAS, D. (1984). Palmares: A Guerra dos Escravos. Porto Alegre, Mercado Aberto.

FRIEDEMANN, N. S. (de 1988). Cabildos negros: refugios de Africania en Colombia. Caracas, Universidad Católica Andres Bello.

FUNARI, P. P. A. (1991). A caricatura gráfica e o ethos popular em Pompéia. São Paulo, manuscrito inédito.

GIDDENS, A. (1987). Social Theory and Modern Sociølogy. Cambridge \& Oxford, Polity.

GUIMARĀES, C. M. \& LANNA, A. L. D. (1980). Arqueologia de Quilombos em Minas Gerais, Pesquisas, 31, 164-163. 
GUIMARẼS, C. M. et alii. (1990). O Quilombo do Ambrósio: lenda, documentos e Ar. queologia. Belo Horizonte, UFMG, manuscrito inédito.

GUTIÊRREZ, H. (1988). Resenha, Estudos Econômicos, 18, 185-6.

GUTIÉRREZ, H. \& MONTEIRO, J. M. (1990). A escravidão na América Latina e no Caribe. São Paulo, UNESP.

HANDSMAN, R. (1985). Thinking about Historical Archaeology of Alienation and Class Struggle, paper at the Annual Meeting of the Society for Historical Archaelogy, Boston.

HOLLAND, C. C. (1990). Tenant farms of the Past, Present and Future: an ethnoarchaeological view, Historical Archaeology, 24, 4, 20-8.

HOWSON, J. E. (1990). Social relations and material culture: a critique of the Archaeology of Plantation Society, Historical Archaeology, 24, 4, 78-91.

MACHADO, M. H. P. T. (1988). Em torno da autonomia escrava: uma nova direção para a História social da escravidão, Revista Brasileira de História, 8, 16, 143-160.

MARTINS, R. B. \& MARTINS FILHO, A. (1984). Slavery in a nonexport economy. a reply, Hispanic American Historical Review, 64, 1, 135-146.

MOURA, C. (1972). Rebeliōes da Senzala. Quilombos, insurreições, guerrilhas. Rio de Janeiro, Conquista.

MOURA, C. (1987). Quilombos, resistência ao escravismo. São Paulo, Ȧtica.

OLIVEIRA e OLIVEIRA, E. (1984). Teses, in AA.VV. Trabalho escravo, economia e sociedade. Rio de Janeiro, Paz e Terra, 1975, 69-72.

ORSER, C. E. (1988). Towards a theory of power for Historical Archaeology, Plantation and Space, in LEONE, M. P. \& POTTER Jr., P. P. (eds), The recovery of meaning: Historical Archaeology in the Fastern United States, Washington, Smithsonian Institution, 313-343.

ORSER, C. E. (1989). On plantation and patterns, Historical Archaeology, 18, 2, 28-40.

ORSER, C. E. (1990). Archaeological approaches to New World plantation slavey, in SHIFFER, M. B. (ed), Archaeological Method and Theory, vol. 2, Tucson, University of Arizona Press, 11-154.

ORSER, C. E. (1990). Historical Archaeology on Southern Plantation and Farms: introduction, Historical Archaeology, 24, 4, 1-6.

REIS, J. J. (1988). Magia Jeje na Bahia, a invasão calundu do Pasto de Cachoeira, Revista Brasileira de História, 8, 16, 57-81.

ROSENBERG, B. A. (1980). Was there a popular culture in Middle Ages?, Journal of Popular Culture, 14, 1, 149-154.

SANTOS, J. R. (1985). Zumbi. São Paulo, Moderna.

SCHWARTZ, S. B. (1977). Resistance and accomodation ion the 18th. century Brazil: the slaves view of slavery, Hispanic American Historical Review, 57, 1, 69-81.

SCHWARTZ, L. M. (1987). Retrato em branco e negro. Jornais, escravos e cidadãos em São Paulo no final do século XIX. São Paulo, Cia. das Letrảs.

SCHWARTZ, S. B. (1988). Segredos internos. Engenhos e escravos na sociedade colonial, 1550-1835. São Paulo, Cia. das Letras.

SINGLETON, T. A. (1990). The archaeology of the Plantation South: a review of approaches and goals, Historical Archaeology, 24, 4, $70-7$.

SLENES, R. (1988). Lares negros, olhares brancos: histórias da família escrava no século XIX, Revista Brasileira de História, 8, 16, 189-203.

STEIN, S. (1969). Grandeza e decadência do café no Vale do Paraíba. São Paulo, Brasiliense. 
STINE, L. F. (1990). Social inequality and turn-of-the-century farmsteads: issues of class, status, ethnicity and race, Historical Archaeology, 24, 4, 37-49.

TAVARES BASTOS, A. C. (1975). Cartas do Solitário. São Paulo, Cia. Ed. Nacional. (1863).

VALVERDE, O. (1965). La fazenda de cafe esclavista en el Brasil. Mérida.

VIOTTI DA COSTA, E. (1982). Da Senzala à Colônia. São Paulo, Brasiliense, (1966).

ZANETTINI, P. (1991). Ouro e Ciência no meio da mata, Novaciência, 13-6.

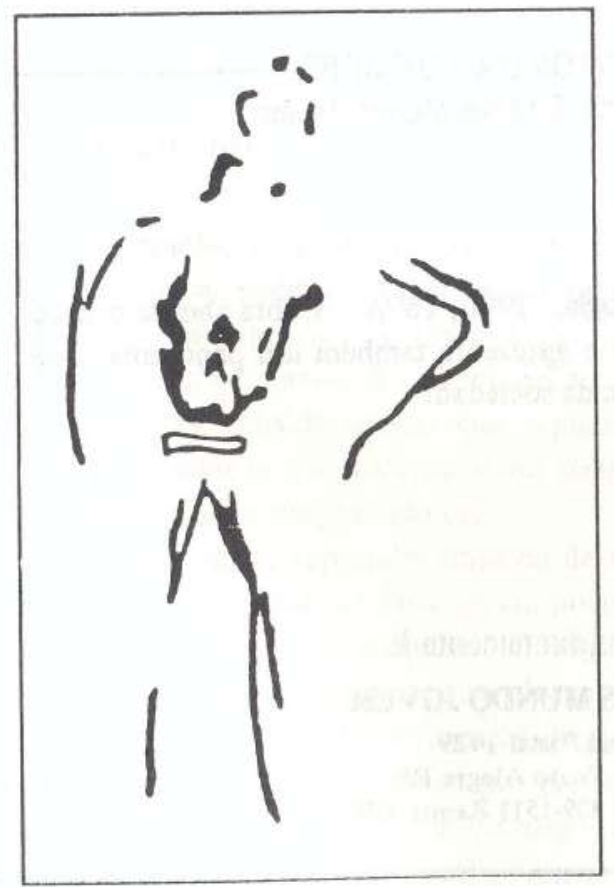

FIGURA 1:

Detalhe do Painel do Quilombo da Cabaça, segundo Guimarães \& Lanna (1980:163) 